\title{
RODOLFO VÁZQUEZ
}

\section{Algunos aspectos de la genética actual y su valoración ética}

Hace poco menos de un año, los medios publicitarios dieron a conocer el décimo aniversario de Louise Brown, el primer bebé logrado en Inglaterra por fecundación in vitro (FIV) y traslado de embrión (TE). Desde 1978 hasta nuestros días han sido numerosos los nacimientos por este método y las clínicas especializadas se han multiplicado en el mundo.

En 1984, dos casos llamaron la atención de la opinión pública. El primero fue el nacimiento de la niña australiana Zoe Leyland, el 13 de mayo, a partir de un embrión que había permanecido congelado durante dos meses. El segundo, conocido como affair Parpalaix, llevó al Tribunal de Grande Instance de Créteil a resolver favorablemente, por sentencia del lo. de agosto, la demanda de la viuda Corinne Parpalaix a que se le entregara el semen depositado del esposo para su inseminación. Intentada lá inseminación post mortem, fracasó.

Pero probablemente, el caso más comentado hasta la fecha sea el de $B a b y$ M. Como se sabe, el 6 de febrero de 1985 se celebró un contrato de maternidad subrogada (suplente o sustituta) entre la señora Whitehead, su esposo y el señor Stern, padre natural o biológico. La señora Whitehead fue inseminada artificialmente con el semen del señor Stern, procreando una niña que nació el 27 de marzo de 1986. Establecida la controversia legal que no es el caso detallar ahora, el tribunal inferior resuelve el 31 de mayo de 1987 que el contrato es válido, beneficiando así al padre biológico. Sin embargo, ante la apelación presentada por la señora Whitehead, el Tribunal Supremo del Estado de New Jersey resolvió el 3 de febrero de 1988 revocando unánimemente, casi en su totalidad, la decisión del Tribunal Inferior. En consecuencia, se declaró que la madre subrogada - biológica y gestanteera la madre legal de la criatura. A su vez, la adopción de ésta por la señora Stern se declaró inválida e ineficaz.

Así los hechos, no deben extrañar que a partir de los primeros éxitos obtenidos por inseminación artificial (IA), los avances alcanzados y las 
perspectivas a futuro sean asombrosos. ${ }^{1}$ Como era de esperarse, paralelamente a los avances técnicos, se ha desarrollado una fecunda reflexión moral que ha puesto a prueba los principios de cada una de las grandes teorías, oscilando las respuestas entre las que pugnan por un rechazo a toda interferencia de la técnica en los procesos naturales reducidos, por lo general, a los biológicos, hasta las que aceptan indiscriminadamente cualquier interferencia bajo criterios crudamente utilitarios. La variedad de respuestas no debe llamarnos la atención si pensamos un poco en la complejidad de los problemas: En el supuesto de la inseminación artificial conyugal (IAC), ¿̇e justifica, éticamente, el procedimiento? ¿debe ponerse algún reparo en la necesidad de la masturbación para conseguir el semen? ¿se justifica la inseminación homóloga con semen del marido luego de su fallecimiento, la llamada inseminación post mortem? En el caso de la inseminación artificial con donante (IAD), de nueva cuenta ¿se justifica, éticamente, el procedimiento? ¿debe quedar abierta la posibilidad de inseminación para las mujeres no casadas actualmente (solteras, viudas, divorciadas, concubinas, lesbianas) como una muestra de respeto al derecho de toda mujer a procrear? ¿debe mantenerse el anonimato del donante o tiene derecho el hijo a conocer su filiación genética? ¿es legítima alguna remuneración económica para el donante? ¿debería renunciar éste a la patria potestad en favor de un tercero anónimo? Por lo que respecta a la fecundación in vitro y desde el punto de vista del embrión logrado, ¿cuál debe ser su estatuto ético-antropológico? ¿es una cosa? ¿es una persona? ¿ puede ser objeto de donación, compra-venta o adopción? ¿se justifica su congelamiento? ¿puede ser manipulado para efectos de investigación y experimentación? Pero además, si le fuera imposible a la madre gestar al embrión ¿se justifica, éticamente, su implantación en el útero de otra mujer, la llamada con propiedad, maternidad sustituta? ¿qué criterio se debe seguir para determinar la maternidad? ¿el gené-

${ }^{1}$ Por mencionar sólo algunos de estos avances: la separación de los espermatozoides más activos en un inteno de asegurar que sólo los más saludables lleguen a fecundar el 6vulo; el rompimiento de la capa externa del 6 vulo por medios químicos reduciendo así el número de espermatozoides de calidad que se precisan para conseguir la fecundación; la transferencia intratubárica de gametos (TIG); la congelación y descongelación de óvulos y embriones por largos periodos de tiempo; la microcirugía que trae como resultado idénticos gemelos o trillizos; la clonización de embriones que posibilitaría una descendencia numerosa e idéntica; la inyección de material genético una vez identificadas las secuencias de DNA asociadas con varias enfermedades genéticas; la utilización médica del tejido fetal y la transferencia de células de un embrión de 2 o 3 semanas a niños o adultos que padecen alguna anormalidad que afecta las funciones vitales del cuerpo; el trasplante de ovarios como otro recurso para superar la esterilidad; la placenta artificial para mantener con vida fetos expulsados por aborto espontáneo cuando tienen 10 semanas, etc. Para una introducción a la genética actual y sus problemas, véase Carl Wood y Ann Westmore, Fecundación "in Vitro", Fontanella, Barcelona, 1984. 
tico? ¿el gestante? ¿el intencional-afectivo?

A los problemas éticos se suman los problemas jurídicos con todas sus sutilezas, por lo demás necesarias, si se quieren proteger adecuadamente los derechos de todos los actores implicados: las personas que solicitan el método, los hijos nacidos por el método, y los terceros que pueden o no intervenir, donantes y madres sustitutas. La nueva realidad, qué duda cabe, es un reto a la imaginación del jurista quien se ha visto en la necesidad de replantear algunas instituciones clásicas de derecho civil que ya resultan incompletas o simplemente ineficaces. ${ }^{2}$ Así por ejemplo, con base en la legislación vigente y ante la posibilidad de la fecundación post mortem se plantea la situación de que el hijo pudiera ser genéticamente conyugal pero jurídicamente extramatrimonial si su nacimiento tuviera lugar después de los 300 días posteriores a la muerte del esposo, plazo que señala la ley (324-II C.C.) para presumir que se trata de hijo de los cónyuges. La interrogante que surge es que en el caso de que la viuda probara que fue fecundada con semen de su esposo ¿podría calificarse a ese hijo como fuera de matrimonio? Además, los hijos que no estén concebidos al tiempo de la muerte del autor de la herencia son incapaces de adquirir por testamento a causa de su falta de personalidad jurídica (1314 C.C.) con lo cual el hijo póstumo quedaría excluido. ¿Es justa esta situación para el hijo? Por otra parte, creemos que la respuesta que se dé a la pregunta anterior lleva implícita una toma de posición con respecto a la noción misma de personalidad jurídica porque si bien la ley reconoce que existe personalidad desde el momento de la concepción 22 C.C. "... desde el momento en que un individuo es concebido entra bajo la protección de la ley...", que se confirma con los artículos $1314,1638,1391$ y 2357 C.C. que corresponden a la posibilidad de que el concebido sea heredero, legatorio o donatorio, y con el 329 C.P. que

${ }^{2}$ Para los problemas ético-jurídicos que plantea la genética actual se puede consultar con provecho: Eduardo Zannoni, Inseminación artificial y fecundación extrauterina, Astrea, Bs.As. 1978; Alberto Di Ció La inseminación artificial y el derecho de la familia, Belgrano, Bs.As., 1984; Manuel Chávez Asencio, La Familia en el Derecho, Porrúa, México, 1987, T. III - de los pocos juristas mexicanos que han tratado el tema cón lucidez de acuerdo con nuestra legislación vigente y a quien personalmente debemos muchos de los cuestionamientos jurídicos-; Pedro Silva Ruiz, "El derecho de familia y la inseminación artificial in vivo e in vitro",Revista del Colegio de Abogados de Puerto Rico, Vol. 48, enero-mayo, 1987, no. 1 pp. 2535; "El contrato de maternidad sustituta o suplente o subrogada, la maternidad de alquiler", Boletín de Información del Ministerio de Justicia, Madrid, España, febrero1987, no. 447. De especial importancia para el tema son las ponencias presentadas tanto en el II Congreso Mundial Vasco (28-IX al 2-X-de 1987) con el título La Filiación a finales del siglo XX, como en el Congreso Hispanoamericano de Derecho de Familia celebrado en Cáceres, España (ocțubre-noviembre de 1987) con el título La Genética actual y el derecho de familia. Entre los ponentes figuraron E. Zannoni, P. Silva Ruiz, Fco. Lledó Yagüe, V. Montés Penagés, J. Guitrón Fuentevilla, Fco. Rivero Hernández, E. Roca Trías, y otros destacados juristas. 
define al aborto como la muerte del producto de la concepción en cualquier momento de su preñez) sin embargo, de aceptarse que el hijo póstumo tuviera igual derecho que los demás hijos a disfrutar de la herencia creo que habría que pensar en alguna excepción al 1314 C.C. ya citado, reconociéndole personalidad antes de la concepción con la sola existencia del semen del marido y la voluntad de los cónyuges para la inseminación. Esta situación ces posible, jurídicamente?

La revisión jurídica se hace necesaria también con respecto a los problemas que suscita la IAD y FIV con donante. Pensemos en lo relativo al reconocimiento de la criatura. Los artículos 325 y 326 C.C. no pueden ni deben aplicarse a esta situación. Por otro lado, ¿qué figura jurídica sería la apropiada para determinar la relación padre-hijo? ¿La adopción? Hasta la fecha la figura de la adopción supone al menor ya nacido (implícito en 390 C.C.) pero aquí estamos hablando de un preembrión (o germen). Por lo tanto, o se inventa una nueva figura jurídica o se extiende la posibilidad de la adopción hasta el preembrión. Asimismo, por lo que hace a la posibilidad de contradecir la maternidad, la mujer queda totalmente imposibilitada (60 C.C.) pero ¿qué sucedería en el supuesto de que se engañe a la mujer haciéndole creer que el óvulo usado para la fecundación fue el suyo y resulta que fue el de una mujer extraña?

La situación de la madre sustituta, en el sentido propio de este término, cuando únicamente gesta a la criatura pero no aporta su óvulo, plantea otros problemas interesantes. Por lo pronto, obliga a replantear el principio de que la filiación con relación a la madre resulta del sólo hecho del nacimiento (360 C.C.) ya que hay un desfase entre el origen biológico del niño (criterio para determinar la filiación consanguínea) y su gestación.

Por último - para cerrar estos planteamientos jurídicos-, en la legislación se percibe el deseo de que el hijo nazca en el seno de una familia y más concretamente dentro del matrimonio. Sin embargo ¿jpodría hacerse extensiva la posibilidad de que una pareja heterosexual estable no casada accediera a la IA y FIV? No olvidemos que la legislación mexicana dio un gran paso en 1983 al eliminar la distinción entre hijos legítimos e hijos ilegítimos y sustituirla por la de hijos dentro del matrimonio e hijos fuera del matrimonio, reconociendo para estos últimos el derecho a llevar el apellido paterno de sus progenitores, a ser alimentados y a percibir la porción hereditaria (389 C.C.). Explícitamente, el 383 C.C. reproduce las presunciones del correspondiente 324 C.C. ahora para los hijos del concubinario y concubina. Y, si bien es cierto que el acento de estos artículos está puesto en la protección de los hijos, no cabe duda, que indirectamente existe un reconocimiento al hecho, muy extendido en México, del concubinato. El acceso de concubinos a la IA y FIV podría ser una prolongación de ese reconocimiento que ayudaría a muchas parejas sin debilitar, necesariamente, los valores del matrimonio.

Pues bien, los problemas a nivel jurídico podrían multiplicarse pero 
no obstante lo importante que resulta este punto de vista, nos limitaremos a señalar, en lo que resta de esta nota, algunos criterios éticos que nos darán la pauta para contestar varias de las preguntas formuladas inicialmente. Estamos convencidos de que las respuestas a nivel moral son el punto de partida para la construcción o actualización de toda legislación. Se podrá estar de acuerdo o no con los criterios pero lo que es claro es que, ante realidades nuevas como es el caso, no existe proyecto de ley o legislación que no suponga una toma de posición éticoantropológica que sirva de base para toda su elaboración. En este entendido ¿qué podemos decir desde el punto de vista ético?

Por lo pronto, creemos que la ética que mejor responde a los problemas que plantea la genética actual, es la personalista. Entendemos por ésta la que considera como criterio objetivo de valoración moral a la persona, su inviolabilidad, autonomía y dignidad, así como sus fines y su proyecto histórico de vida.

La persona se nos manifiesta como una realidad simultáneamente biológica y racional, individual y comunitaria, completa y perfectible. Esto significa, entre otras cosas, que la persona no se agota en su estructura y dinamismo físicos; por lo tanto, no debe ser el orden natural biológico el criterio único de moralidad. Sacralizar el carácter biológico de la persona ha llevado a muchos moralistas a excluir todo tipo de intervención humana en los procesos naturales dando lugar, no pocas veces, a una ética dogmática, absolutista pero, sobre todo, inhumana. Si la técnica auxilia a la persona en el cumplimiento de sus fines y permite, a través de los métodos de reproducción asistida, superar una carencia grave como es la esterilidad, que afecta entre un 10 y $15 \%$ de las parejas en edad de procrear, no hay razón para evitar a-priori su puesta en práctica. La IA, FIV y TIG, como tales, no son censurables, suplen deficiencias en el proceso reproductor de la pareja.

Pero, de igual manera, si privilegiamos la racionalidad de la persona sin limitación alguna a sus deseos, intereses o preferencias podría conducirnos a una falta de respeto a su dignidad e integridad que también se traduce en un desarrollo biológico ordenado. Por lo que, si los métodos de reproducción asistida tienen como finalidad fundamental superar la esterilidad para facilitar la procreación, su aplicación tiene sentido cuando otros medios terapeúticos se han descartado por inadecuados o ineficaces. De no mediar la esterilidad no se justifica su uso para satisfacer, únicamente, los deseos de la pareja, mucho menos para ir con la moda, por simple esnobismo o fines estéticos.

Pensamos que el matrimonio es el ámbito ético-jurídico-social aceptable para la realización de los métodos de reproducción asistida. Entendemos por matrimonio a la pareja heterosexual que adquiere un "compromiso público y permanente de vida conyugal" y que tiene como fin el amor entre esposos, la promoción integral de la pareja y la procreación responsable. ${ }^{3}$ Deliberadamente nos ubicamos en el derecho del

${ }^{3}$ Véase Manuel Chávez Asencio, Matrimonio, compromiso jurídico de vida conyu- 
hijo a una vida estable y rechazamos la idea de que exista en la mujer un derecho al hijo que haría a este último, que es fin en sí mismo, un medio al servicio de ios deseos o intereses de otra persona. Desde este punto de vista, las parejas homosexuales, la mujer soltera y las personas en unión inestable no deben tener acceso a preembriones (o gérmenes), semen u óvulos donados. ${ }^{4}$ Reiteramos, el derecho de toda mujer a ser madre no es un derecho absoluto que exija su cumplimiento al margen del derecho del hijo a una vida ética, jurídica y socialmente estable. La maternidad-paternidad deben entenderse en función del hijo y no al revés. Con todo, pensamos que no debe excluirse del acceso a los métodos de reproducción asistida a las parejas estables no casadas, entendiendo por éstas "a la pareja heterosexual que mantenga una relación similar al matrimonio, y asuma, respecto de los hijos, los derechos y obligaciones de aquél" ${ }^{5}$ Es cierto que la carencia actual de regulación de las condiciones en que se desarrollan las uniones de facto por lo que hace a un acuerdo sobre el tiempo mínimo de duración, la ausencia, en muchos casos, de una aceptación pública y los derechos y obligaciones que contrae la pareja, no ofrece un contexto de seguridad apropiado para el buen desarrollo del hijo. Pero si éste es el tipo de razones para impedir su acceso a los métodos, pensamos que no son insuperables y más que un rechazo debe hacerse un esfuerzo ético y jurídico para hacer compatible el derecho de la pareja estable a formar familia y el derecho del hijo a un clima de plena seguriciad y aceptación social.

Con respecto al estatuto ético-antropológico del preembrión (o germen), del embrión y del feto hemos desarrollado, en otra parte, algunas ideas relacionándolas con el problema del aborto. ${ }^{6}$ Resumiendo, pensamos que la personalización y hominización del embrión no es inmediata, desde el instante mismo de la fecundación, sino mediata cuando el embrión ha alcanzado un desarrollo orgánico adecuado. En virtud del acto generador humano, el cigoto es un supuesto que desde el primer instante es hecho para ser hombre y llegará a ser formalmente aquello que desde el inicio es virtualmente por el impulso radical del que depende. Su índole humana se encuentra asegurada por hechos psico-biológicos, como son el correspondiente código y mensaje genéticos que lo hacen ser individual, independiente del organismo materno y moralmente

gal, Limusa-UIA, México, 1988.

${ }^{4}$ En este punto recogemos las ideas expresadas por buena parte de la doctrina, así como por la mayoría de las Comisiones, en especial, los informes del Consejo de Europa y el informe Warnock en el Reino Unido, ambos de 1984. También, las propuestas de ley italiana y francesa, y la ley sueca que entró en vigor el $1^{\circ}$ de marzo de 1985.

${ }^{5}$ Artículo 7o, 2, de la Proposición de Ley sobre Técnicas de Reproducción Asistida tramitada por la Comisión de Política Social y Empleo y publicada en el Boletín Oficial de las Cortes Generales (B.O.C.G.) de España, el 27 de mayo de 1988. (La Ley vigente del 24 de noviembre de 1988 eliminó la noción de "pareja estable").

${ }^{6}$ ESTUDIOS 14, Otoño de 1988, pp. 27-57. 
relevante, pese a que su ser como persona lo adquirirá en un periodo posterior. No es una cosa, tampoco es aún formalmente persona, es un supuesto virtualmente persona que es razón suficiente, si no existe conflicto de valores, para respetar su autonomía y dignidad. Por lo tanto, los preembriones (que corresponden a la fase de preorganogénesis, desde la fecundación hasta aproximadamente 14 días más tarde, cuando anida establemente en el interior del útero) no deben ser objeto de donación, compraventa o depósito, contratos que suponen un bien patrimonial. Tampoco es justificable éticamente, la utilización de preembriones con fines de experimentación (donación, partenogénesis, fusión de preembriones entre sí, intercambio genético con otras especies para producir híbridos, la transferencia en el útero de otra especie animal, etc.) o para fines industriales. Pero no vemos impedimento alguno para que, por una parte, se puedan usar los gametos (semen y óvulo) por separado con fines de investigación o experimentación; y por otra, para que el mismo preembrión pueda ser objeto de investigación con fines de diagnóstico (valoración de su viabilidad o no, o detención de enfermedades hereditarias) o terapeúticas (tratar una enfermedado impedir su transmisión). Por otra parte, y de acuerdo con Zannoni, ${ }^{7}$ dada la autonomía y dignidad del preembrión no se justifica que se le exponga a un estado de incertidumbre y desamparo. Nos referimos a los llamados "embriones sobrantes". Creemos que toda FIV debe realizarse con el solo fin de implantar el o los embriones en el útero materno y no someterlos a situaciones aleatorias. Por lo tanto, la admisión de fertilizaciones múltiples es aceptable a condición de que todos los embriones sean implantados. Hoy día, además, ya es posible limitar la fecundación al número de embriones necesarios para la implantación. No excluimos la posibilidad y la necesidad, en muchos casos, de su congelación pero la pareja debe estar consciente de que todos los embriones le serán implantados. Si la pareja, como dice Zannoni, no está en condiciones actuales de llevar adelante el embarazo, no resulta justificado realizar fertilizaciones ahora para posibilitar implantaciones después.

Señalados algunos criterios generales de valoración ética para los métodos de reproducción asistida, podemos pasar al análisis de aquellas situaciones particulares que dependen más directamente de los actores implicados: pareja que solicita método, donantes y madre sustituta.

La IAC u homóloga, esto es, con semen del marido (o del hombre en la pareja estable) y la FIVTE homóloga, con óvulos de la mujer y semen del marido (o de la pareja estable), no presentan ningún conflicto ético. No hay un rechazo de la pareja a la cópula como medio ordinario para la procreación sino que existe carencia (la esterilidad) que la imposibilita.

${ }^{7}$ Eduardo Zannoni, La Genética actual y el derecho de familia, ponencia presentada en el Congreso Hispanoamericano de Derecho de Familia. 
Los métodos de reproducción asistida se utilizan, entonces, como una situación remedial y supletaria. De paso, es conveniente señalar que con respecto a la recogida del semen a través de la masturbación hay que distinguir entre la llamada masturbación moral en la que aisla el sexo de la relación yo-tú y se usan egocéntricamente, y la masturbación biológica que es la que nos interesa ahora, y que, a nuestro juicio, no debe presentar ningún escrúpulo de carácter ético. Es una exigencia biológica necesaria, semejante a lo que sucede con los tests de esterilidad que requieren, igualmente, del semen. ${ }^{8}$

La IA post mortem con semen del marido puede justificarse éticamente dada la fuerza moral e institucional del matrimonio aunque éste ya quede disuelto por la muerte del cónyuge. Coincidimos en esta valoración con los puntos de vista expresados por Rivero Hernández. ${ }^{9}$ Contra la IAC post morten se aduce -como cuando se trata de mujer sola-que el hijo se vería condenado a nacer y vivir sin padre, lo que va en contra de su interés y bienestar. En efecto, el hijo tiene derecho a tener padre y madre pero "quizá el derecho del hijo en ese terreno no es tanto el de tener padre y madre como dos seres que le acompañen físicamente, sino a que ambos le proporcionen una serie de cosas que hagan visible una existencia a la que le han traído por exclusiva decisión de aquéllos". Por otro lado, la situación de la IAC p.m. no es igual a la de mujer sola, "En este caso el hijo nace (no sólo vivirá) sin padre. En aquél el hijo sí va a tener padre; no lo conocerá materialmente, no disfrutará de él, su protección y afecto, pero no es hijo sin padre, o de padre desconocido". El hijo tendría una relación de filiación, y con la familia del padre otra de parentesco. Además el hijo será hijo de matrimonio, si se demuestra que fue engendrado por el marido, aun pasados los 300 días, pues "el consentimiento para la fecundación p.m. del marido fallecido, conjugado con la decisión de la viuda a ser inseminada, responden a un proyecto común de dar vida a un hijo de ambos" y creemos que esta voluntad es el factor determinante para que podamos justificar la inseminación y hablar de hijo dentro del matrimonio. Además del consentimiento del marido, entre otros requisitos, habría que exigir que la inseminación tuviera lugar dentro de un plazo razonable (lo que hablaría de la buena fe de la pareja): un año, prorrogable, si hay causa justificada como puede ser alguna enfermedad de la mujer.

Con respecto a la IAD o heteróloga, es decir, con semen de donante, ola FIVTE con gametos masculinos o femenino, donados, no nos parece justificable, éticamente. Creemos que en esta posibilidad se lesiona el principio básico de la comunidad conyugal; se desvirtúa el sentido de la maternidad-paternidad humanas y trae problemas psicológicos con respecto a la asimetría en la relación madre-hijo y padre-hijo. En estos

${ }^{8}$ Véase Marciano Vidal, Moral de Actitudes III, Ed. P. S., 1985, p. 340. quien se apoya, a su vez, en la opinión de Havering, Spoken, Di Ianni y Rossi.

"Véase Francisco Rivero Hernández, La Fecundación artificial "post mortem", poncncia presentada en el Congreso Hispanoamericano de Derecho de Familia. 
casos, nos parece que la adopción es una alternativa más adecuada.

Consciente de que han quedado muchos puntos a discutir, vamos a finalizar esta nota con una breve reflexión sobre la maternidad subrogada. Sabemos que dado el embrión por FIV se produce a su traslado (TE) en el útero de la madre. Pero, en el caso de que ésta no pudiera gestarlo ¿sería justificable, éticamente, su traslado al útero de otra mujer para que se geste? El supuesto que estamos considerando es el de la gestación por otra mujer pero con aportación por la pareja de los gametos. Las posibilidad de la gestación en útero ajeno con aportación por la gestante del óvulo cae dentro de la AID, que ya consideramos en el párrafo anterior. Con respecto, entonces, a la sola gestación en útero extraño no vemos impedimento ético alguno para que se pueda llevar a cabo. Como es obvio, la noción que está implícita en la afirmación anterior es la de maternidad y aunque los informes y los proyectos de legislación se están inclinando por privilegiar la maternidad de gestación, los criterios no son tan claros. Desde nuestro punto de vista, la razón formal, lo que especifica la maternidad es la intención, deseo o voluntad de ser madre, con todo lo que esta intención significa en términos de cuidado, afecto, alimentos. Esta razón es determinante, por ejemplo, para justificar la adopción y no sólo la adopción limitada, que es la que acepta nuestra legislación vigente (402 C.C.), sino la adopción plena por la cual el niño se integra totalmente a la familia de los adoptantes. Pero junto a la maternidad intencional afectiva como causa formal nos parece que como causa material correspondiente debe considerarse el aporte genético de la pareja. Es éste el que individualiza o concreta la razón formal de la maternidad. Y es en la unidad de ambas causalidades, material y formal, que se define propiamente la maternidad. La gestación, que indudablemente conlleva un valor físico y afectivo reforzador que contribuye a la plenitud de la maternidad, no es un elemento necesario para su determinación. Bajo ciertas condiciones -y entre ellas una de las más importantes es la no mediación de un convenio lucrativo-no vemos razón para que no se pueda auxiliar a la mujer que está incapacitada para gestar, a través de un útero sustituto. Coincidimos, en este punto con Merino Gutiérrez cuando afirma que "en los casos de utilización de útero ajeno la gestación sustituta es secundaria respecto al material genético incorporado. En esta línea sería partidario de inscribir la filiación como matrimonial o no matrimonial en las condiciones ya señaladas por algunos autores de que concurra un acuerdo previo, antes de la implantación del embrión, que conste por escrito en documento público, entre la pareja y la mujer portadora; un documento del centro donde se practicó la implantación asegurando que el material genético corresponde efectivamente a la pareja y, por último, la ausencia de oposición de la gestante sustituta una vez que ya ha dado a luz". ${ }^{10}$ No está lejos el día en que se pueda gestar a la criatura a través de placenta artificial desde

${ }^{10} \mathrm{~A}$. Merino Gutiérrez, Los consentimientos relevantes y las técnicas de reproducción asistida, ponencia presentada en el I I Congreso Mundial Vasco. 
las primeras semanas o incluso desde la fecundación, lo que, sin duda, sería otra alternativa para solucionar los casos de incapacidad gestativa. 